between radiologists in the interpretation of the venogram as to whether thrombus was present or not. Nevertheless this group of patients was a worry to us and we have since performed a telephone follow up of 120 of the cases between six and 12 months after their initial treatment. None of these patients had suffered further thrombosis or pulmonary embolus. All were still alive and none had been admitted to another institution.

We agree that the clinician should maintain a low threshold of suspicion for DVT despite a negative LRR. We also agree that the SimpliRed D-dimer assay is useful and we have just completed a study of several hundred patients using this $\mathrm{D}$-dimer assay. The negative predictive value in our study was similar at $95 \%$. We feel the test has a strong part to play in the screening of patients for DVT as long as they have no other cause for fibrinolysis, for instance they are not postoperative or suffering from certain medical conditions such as sepsis or myocardial infarction. It is probably the screening method of choice out of hours as it is easy and quick to perform when other more sophisticated tests may not be available.

\section{Empirical thrombolysis in catastrophic pulmonary embolism}

EDITOR,-I was interested to read the report by Kehoe and Dacruz in which administration of recombinant tissue plasminogen activator (rt-PA) during cardiac arrest secondary to pulmonary embolism in a 69 year old woman resulted in restoration of the circulation and subsequent full recovery. ${ }^{1}$

The authors may be interested in a review by Bottiger et al who have collected data on a total of 48 patients (case reports and three small case series) with cardiac arrest secondary to pulmonary embolism treated with thrombolysis (either with streptokinase, urokinase, or rt-PA) during cardiopulmonary resuscitation (CPR). ${ }^{2}$ Data from the three smal case series showed initial survival rates of $55 \%-100 \%$. In successful cases, spontaneous circulation was re-established in as little as 10-20 minutes after administration of thrombolysis, though successful resuscitation was recorded in cases where CPR was continued for up to 90 minutes after thrombolysis. The authors favoured use of rt-PA or urokinase over streptokinase in view of the latter's propensity to cause hypotension.

Given that cardiac arrest caused by pulmonary embolism is usually refractory to conventional resuscitative efforts, these data, together with the case reported by Kehoe and Dacruz suggest that thrombolysis should be considered in cases of cardiac arrest associated with pulseless electrical activity where suspicion for underlying pulmonary embolism is strong.

$$
\begin{array}{r}
\text { J KELLY } \\
\text { Specialist Registrar in Geriatrics/General Internal } \\
\text { Medicine, } \\
\text { Queen Mary's Hospital, } \\
\text { Sidcup, Kent DA14 } 6 L T
\end{array}
$$

1 Kehoe T, Dacruz P. "Empirical" thrombolysis in catastrophic pulmonary embolism. If Accid Emerg Med 1999;16:76.

2 Bottiger BW, Bohrer H, Bach A, et al. Bolus injection of thrombolytic agents during cardiopulmonary resuscitation for massive pulmonary pulmonary resuscitation for massive pulm
embolism. Resuscitation 1994;28:45-54.

\section{Activated charcoal preparations}

EDITOR,-I read with interest Boyd and Hanson's paper on the ingestion of two differing preparations of activated charcoal.' The authors have used a two sample $t$ test to compare the mean mass of charcoal ingested and one of the assumptions of this test is that the data are Normally distributed. While the test is relatively robust to minor deviations from Normality two aspects of the study give cause to concern as to the validity of this assumption for their data. Firstly, the very large standard deviates given in the paper for the mean amount of activated charcoal ingested. These represent the spread of the data and their size indicates possible skewing or non-Normality of the distribution of the data. Secondly, clinical experience would suggest that there would be some clustering of patients ingesting the maximum level (about 45-50 g) or around the minimum level with spread in between, this distribution with a fixed upper limit that is readily achievable would seem unlikely to be Normal.

To support the authors contention that a significant difference exists in mass ingested some evidence of Normality of the distribution would be helpful. This could be simply a histogram of the data to reassure readers of the validity of their conclusions. Alternatively a transformation of the data to Normality and repeat two sample $t$ test could be used. If the data cannot be transformed adequately then the non-parametric equivalent of the two sample $t$ test would be appropriate, the MannWhitney U test.

PETER LEMAN

Honorary Lecturer in Accident and Emergency Medicine, UMDS/Guy's Hospital St Thomas Street, London SE1 9RT

1 Boyd R, Hanson J. Prospective single blinded randomised controlled trial of two orally administered activated charcoal preparations. $\mathcal{F}$ Accid Emerg Med 1999;16:24-5.

\section{The authors reply}

We thank Dr Lehman for his obvious interest in our recent paper. The data for the Actidose and Carbomix ingestions did not strictly conform to routine tests for Normality. However both were relatively symmetrical (especially for Actidose) and the standard deviations are of very similar size. Due to the moderate to large sample sizes ( 47 and 50), it was not considered crucial that the data was Normally distributed. Use of the two sample $t$ test was therefore considered valid.

The histograms of the ingested doses show that the Actidose appeared to have a greater degree of variability in the ingested amount than the Carbomix (see figs 1 and 2). In fact no patients achieved ingestion of the maximum dose while all but one patient ingested some of the prescribed charcoal preparation. The data do not appear to be clustered at the

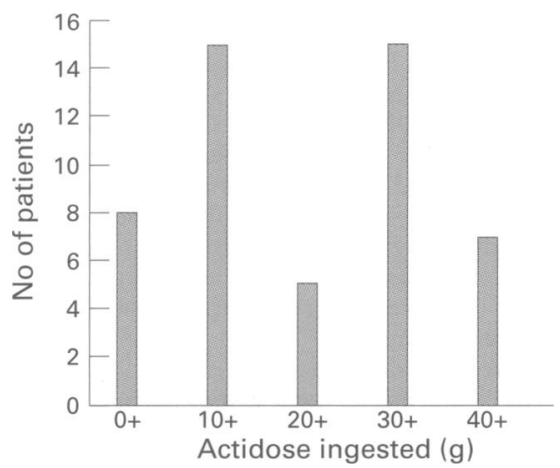

Figure 1 Histogram of the data distribution for Actidose administration.

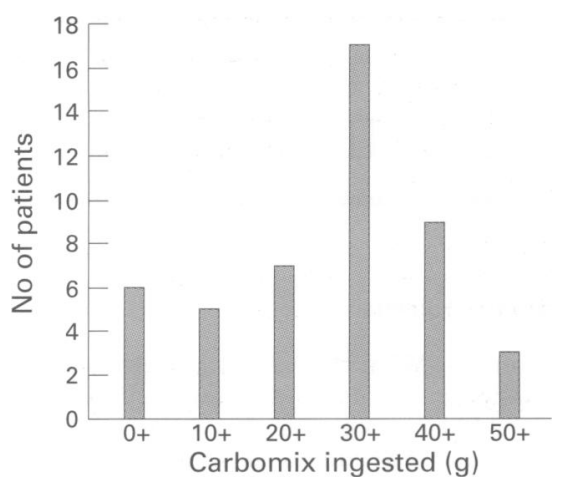

Figure 2 Histogram of the data distribution for Carbomix administration.

extremes of the ingested dosages, as shown by the relatively symmetrical histogram forms.

(Correspondence to: Dr Russell Boyd, Specialist Registrar, Accident and Emergency Department, Hop Hospital, Stott Lane, Salford M6 8HD)

BOOK REVIEWS

Paediatric Toxicology. Handbook of Poisoning in Children. Edited by Nicola Bates, Nicholas Edwards, Janice Roper, Glyn Volans. (Pp 411; £24.95.) Macmillan Reference Ltd, 1997. ISBN 0-333-60951-4.

You wouldn't think that a reference book would be a good read. But like the old Pears Cyclopaedia into which I used to dip as a child to marvel at oddities, paediatric toxicology is full of interesting antidotes. I think it is because many of the recommendations are illustrated by case reports. There is a fascination for doctors in the reading of case reports. They somehow seem more like "real life" than pages of opinion and information. We can apply our own diagnostic skills to the story and there is a personal clinician to patient feel about the reading of a case report.

So much for its entertainment value. Is Paediatric Toxicology a useful book in the management of acute poisoning in children and is it presented in an accessible manner?

The answer to the first question is easily provided by asking users whether they found it helpful in solving problems. Personally I have found useful information in $90 \%$ of the occasions that I have consulted it for individual patients or when preparing teaching. Nurses at our telephone triage point, who spend seven hours a day on average answering phone calls from the public, many of which are about poisonings, tell me that it is useful in about $80 \%$ of the requests that they get for information. It is particularly helpful to reassure parents whose child has taken an innocuous substance.

When it comes to the management of a child who has taken a potentially serious overdose, and particularly one that is not commonly taken (that is, not paracetamol!) then I will still want to individualise the advice by talking to a poisons centre expert. However, these cases are in a small minority.

The presentation of information is easy to access. Page layouts make the book an easy read. We are, of course, still bedevilled in pae- 
diatric emergency medicine by a major lack of "evidence" but this book has useful individually annotated reference lists of what are mainly small case report series.

In conclusion I recommend this book to all paediatric and accident and emergency departments and also to primary care centres. The volume purchased for this hospital early after publication is now battered enough to demonstrate its usefulness.

B M PHILLIPS Consultant in Paediatric Emergency Medicine, Liverpool

Clinical and Resuscitative Data. A Compendium of Acute Medical Data. 5th Ed. By Richard Dunnill and Peter Colvin. (Pp 204; £19.95.) Blackwell Science, 1998. ISBN 0-86542-788-7.

The preface to the first edition indicates this book is intended for staff in accident and emergency (A\&E) departments, intensive care, and other resuscitation areas. Sadly, despite this, the authors have not enlisted the help of anyone from $A \& E$ in the preparation of the book. This oversight has lead to the production of a book that cannot be recommended for use within an A\&E department. Although it does contain some useful information, this book contains a great deal that is irrelevant to $A \& E$ staff as well as numerous errors.

I doubt that many who work in $\mathrm{A} \& \mathrm{E}$ need to know, while resuscitating a patient, that the unit of light is a candela nor how to convert from knots to miles per hour. A whole section is devoted to feeding critically ill patients; this is not an issue for $A \& E$.

Among the more serious of the errors this book contains, the algorithms for basic life support (for both children and adults) do not make any mention of summoning the cardiac arrest team or calling 999. Shouting for help is omitted completely from the paediatric algorithm. The adult advanced life support algorithms are not those most recently produced by the Resuscitation Council; this seems quite likely to lead to confusion. The periarrest algorithms are said to be reproduced from those of the European Resuscitation Council but contain omissions. Atrial fibrillation, for example, does not appear in the narrow complex tachycardia algorithm.
There is a section listing drug interactions. I would suggest that the safest way of avoiding inadvertent interactions is by referring to the British National Formulary, especially since this section does omit some potentially fatal interactions (including those involving antihistamines which quite possibly could be prescribed in the A\&E department).

The final section attempts to provide guidance on the management of drug overdosage. I would view most of the advice regarding gastric lavage, induced vomiting and activated charcoal as out of date. A potentially dangerous piece of advice is that $\mathrm{N}$-acetylcysteine can be harmful when administered more than 15 hours after the ingestion of paracetamol. There is good evidence that in paracetamol induced liver failure $\mathrm{N}$-acetylcysteine is of benefit even when started one or two days after ingestion. Finally the recommendation that patients who have taken an overdose of paracetamol should be admitted to an intensive care unit will, I suspect, generate a mixture of amusement and amazement among staff who work in the $\mathrm{A} \& \mathrm{E}$ department.

I cannot comment on the value this book may have for anaesthetists and intensive care doctors but do feel that it has no role at all within $A \& E$ medicine. I would discourage $A \& E$ doctors from buying or using it.

R D HARDERN

Consultant Physician in Acute Medicine and Consultant in Accident and Emergency Medicine,

Leeds

\section{Books received}

Handbook of Orthopaedic Emergencies. By Raymond G Hart, Timothy James Rittenberry, and Dennis T Uehara. (Pp 510; £28.00). Lippincott-Raven, 1999. ISBN 0-7817-1610-1.

Handbook of Interpretation of Diagnostic Tests. By Jacques Wallach. (Pp 564; £18.00.) Lippincott-Raven, 1998. ISBN 0-7817-1221-1.

\section{NOTICES}

Better Practice in Trauma Care, SWAN VII Trauma Seminar

6-7 August 1999, Sydney, Australia

Further details: SWAN Conference Secretariat, Liverpool Hospital, Elizabeth Street, Liverpool, Sydney 2170, Australia (tel: +6129828 3928, fax: +61 29828 3926, e-mail: michael.sugrue@swsahs.nsw.gov.au,web site: http://www.swsahs.nsw.gov.au/livtrauma).

\section{Emergency Care in the Air}

13 September 1999, Queen's Medical Centre, Nottingham

Further details: Education Department, Royal College of Surgeons of Edinburgh (tel: $+44(0)$ 131527 1676, e-mail: education@rcsed.ac.uk, web site: http://www.rcsed.ac.uk/Diary/ emergency_care_in_the_air.htm).

\section{British Paediatric A\&E Group Autumn Meeting}

16 September 1999, Devonshire House, Derbyshire Royal Infirmary

Further details: Mrs Jill Straw, Postgraduate Education Manager, Devonshire House, Derbyshire Royal Infirmary, London Road, Derby DE1 2QY.

\section{2th Annual Congress of the European} Society of Intensive Care Medicine

3-6 October 1999, Berlin, Germany

Further details: ESICM Congress Secretariat, 40 Avenue Joseph Wybran, 1070 Brussels, Belgium (tel: +32 255903 05, fax: + 322527 00 62, e-mail: esicm@pophost.eunet.be, web site: http://www.esicm.org).

\section{Better Practice in Trauma Care, SWAN} VIII Trauma Seminar

5-6 August 2000, Sydney, Australia

Further details: SWAN Conference Secretariat, Liverpool Hospital, Elizabeth Street, Liverpool, Sydney 2170, Australia (tel: +61 29828 3928, fax: +61 29828 3926, e-mail: michael.sugrue@swsahs.nsw.gov.au,web site: http://www.swsahs.nsw.gov.au/livtrauma). 